\title{
Bubble stabilisation improves strength of lightweight mortars
}

Oday H. Hussein BEng, PhD

Research Technician, Department of Materials Science \& Engineering, The University of Sheffield, Sheffield, UK

Susan A. Bernal BEng, DEng

Research Fellow, Department of Materials Science \& Engineering,

The University of Sheffield, Sheffield, UK

Ju-Hyung Ha PhD, PE

General Manager, Research \& Development Division/Advanced Material

Research Team, Hyundai Engineering \& Construction Co, Ltd,

Mabuk-dong, Giheung-gu, Yongin-si, Gyeonggi-do, Korea
John L. Provis BSC, BEng(Hons), PhD, FIMMM

Professor, Department of Materials Science \& Engineering, The University of Sheffield, Sheffield, UK

Lightweight foamed mortars are produced through the addition of foaming agents into the cement blend, so that voids of different sizes are formed within the matrix, reducing the density of the material and therefore also its weight. However, the increased porosity of these materials usually compromises their mechanical strength, limiting their application as a structural material. Modern infrastructure demands high-strength lightweight concrete formulations that can be adjusted to develop more ambitious projects, both in design and application. In this study, lightweight pastes and mortars were produced using Portland cement blended with fly ash and silica fume, with varying water contents, and foamed using aluminium metal powder. To stabilise the bubbles produced through oxidation of the aluminium metal, polyethylene glycol was added to the mixes, and proved effective in yielding more uniform bubbles than were observed in the samples with no added stabiliser. This led to improvements in both the bulk density and compressive strength of the materials produced according to this new methodology.

\section{Introduction}

The use of lightweight concrete in structural or semi-structural applications has long been the target of technological developments, with efforts involving the reduction of unit weight of both the aggregate and the binder having been undertaken for more than 100 years (Valore, 1954). The availability of lightweight concrete as a construction material is particularly topical at present, as the combination of good mechanical and thermal insulation properties offers significant improvements in the energy efficiency of buildings in service without excessive increases in the thickness of the building envelope.

The reaction of metallic aluminium (Al) with the alkaline pore solution of the cement, releasing hydrogen gas and aerating the binder, has long been favoured as a method of reducing the density of a cementitious binder (Aylsworth and Dyer, 1914); this method has been shown to be applicable to a wide range of binder compositions, ranging from the original work of Aylsworth and Dyer with Portland cement and gypsum (Aylsworth and Dyer, 1914) to the more recently developed foamed geopolymer systems (Zhang et al., 2014). However, the production of foamed concretes with sufficient strength to enable their use in structural concrete applications is less straightforward. This material has thus been used largely in applications where value is gained from its insulating properties (thermal and acoustic) and/or the reduction of mass which can lead to lower dead load within a structure and greater ease of handling during construction (ACI Committee 233, 2000).

Recent work on the development of lightweight Portland cement concretes for use as structural materials has shown success in producing materials with compressive strengths exceeding $28 \mathrm{MPa}$ in $28 \mathrm{~d}$, either by the use of a surfactant as foaming agent in combination with coarse fly ash (replacing fine aggregate) and a small quantity of polypropylene fibres (Jones and McCarthy, 2005), or by using a surfactant and silica fume-blended cement in concretes with standard dense fine and coarse aggregates (Lee et al., 2014). In each of these cases, the high strength was provided through the use of goodquality modern Portland cement combined with appropriately selected supplementary cementitious materials for curing at ambient or near-ambient temperature. In particular, the types of binder formulation which would otherwise be used to produce high-performance dense concretes, including the use of microsilica as a pozzolan, are also likely to give the best strength development when used in lightweight materials, and 
so provide the most likely targets for optimisation of the strength-density relationship of foamed concretes.

Elevated-temperature curing is used to form autoclaved aerated concrete, which is often foamed using aluminium metal powder (releasing hydrogen gas as it oxidises under an alkaline environment) (Aroni, 1993); however, this material is generally specified only for strength grades less than $10 \mathrm{MPa}$ (Klingner, 2008). Higher strength materials have been demonstrated through the combination of aluminium metal powder with a microsilicarich Portland cement blend (Just and Middendorf, 2009). It has generally been considered more difficult to achieve the desired stable, highly uniform, small bubble size required for high strength through the use of metallic foaming agents than by the application of a pre-formed organic foam based on surfactants, but the additional processing steps involved in the pre-foaming route pose disadvantages related to that method. It is therefore considered desirable to develop alternative routes to the production of foamed concrete which are more similar, in terms of the required processing steps, to the methods by which standard dense concretes are produced and placed, yielding materials with strengths that are sufficiently high for structural or semi-structural application. This necessitates careful control of the fresh-state properties of the paste, particularly flow characteristics, as foamed paste which requires a high mechanical energy input in pumping and placement is likely to suffer de-aeration as a result.

This study approaches the question of production of moderatestrength, moderate-density foamed mortars through an innovative method of bubble stabilisation in a material system foamed by the addition of aluminium metal. A binder is designed based on Portland cement with microsilica and fly ash, with the bubbles generated through hydrolysis of aluminium metal stabilised by the addition of polyethylene glycol (PEG) as a surface-active agent. This stabilisation mechanism enables the retention of small bubbles within the fresh paste until hardening, resulting in a flowable material which yields a desirable microstructure and good strength performance, suitable for future scale-up to use in concretes.

\section{Materials and methods}

\subsection{Materials}

Portland cement of grade CEM I $52.5 \mathrm{~N}$, with a bulk density of $1506 \mathrm{~kg} / \mathrm{m}^{3}$, was used throughout this study. A commercial low calcium fly ash, classified as 'siliceous' according to EN 197-1 (CEN, 2011) and complying with the requirements of EN 450-1 (CEN, 2012), and silica fume complying with EN 13263-1 (CEN, 2005) were used as supplementary cementitious materials. Aluminium powder, general-purpose grade, was used as the foaming agent. As bubble stabiliser, PEG with an average molecular weight of $20 \mathrm{kDa}$ was used. Quartz building sand, with a particle density of $2650 \mathrm{~kg} / \mathrm{m}^{3}$ and with $100 \%$ passing $2.40 \mathrm{~mm}$, was the fine aggregate in all mortars.

\subsection{Sample preparation}

To select and optimise the amount of foaming agent and water content, preliminary experiments were carried out using paste mixes. Pastes were produced with water to cement ratios of $0.35,0.40$ and 0.45 to span the range from very stiff to very fluid pastes, and aluminium powder contents of 0, 0.3, 0.6 and $0.9 \mathrm{wt} \%$ relative to the cementitious materials in the paste, according to the process depicted in Figure 1.

The workability of the paste mixes was tested according to a mini-slump radius measurement as described in Bouvet et al. (2010). Following the mixing protocol as described in Figure 1, the paste was poured into a polytetrafluoroethylene (PTFE) cone of $40 \mathrm{~mm}$ height, $80 \mathrm{~mm}$ lower diameter and $70 \mathrm{~mm}$ upper diameter, resting on a Lucite sheet marked with a grid, and compacted by rodding with a spatula. After $1 \mathrm{~min}$, the cone was lifted clear from the paste, and the diameter of the pat was measured using calipers and then converted to radius values for presentation.

The paste specimens for analysis were cast in centrifuge tubes, sealed and cured at $21 \pm 2{ }^{\circ} \mathrm{C}$. After $24 \mathrm{~h}$, the bulk density was determined through a measurement of the volume and mass of cylindrical samples, in an as-cured condition immediately upon de-moulding of the specimens.

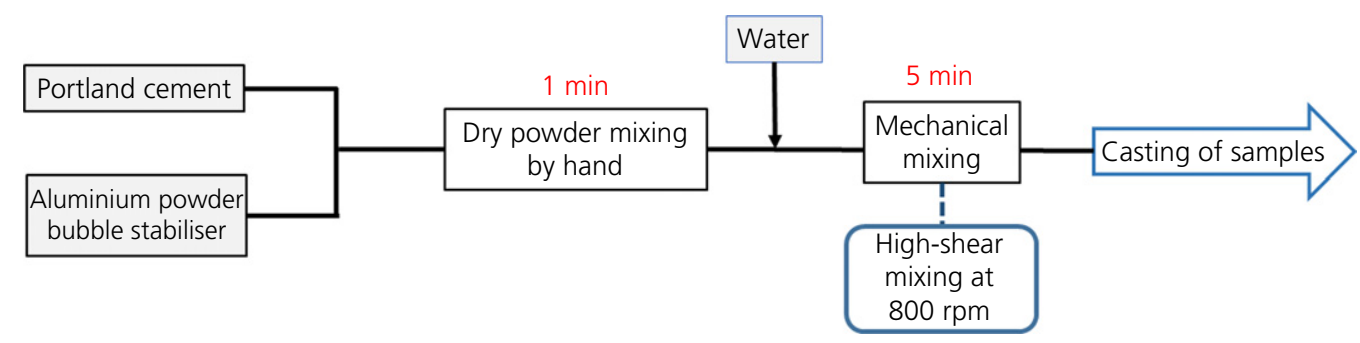

Figure 1. Procedure used for paste preparation 
Photographs of the longitudinal sections of paste specimens after $28 \mathrm{~d}$ of curing were collected using a Veho USB optical microscope with a maximum magnification of $20 \times$.

On the basis of the results of the study of the paste specimens, the optimal foaming agent and stabiliser doses were selected, and mortar specimens were produced (Figure 2) using a Kenwood mixer. Mortar formulations are given in Table 1, where the addition of fly ash was intended to reduce density and enhance workability, and the addition of silica fume was intended to improve early-age strength development. Density was determined through the precise weighing and dimensional measurement of $50 \mathrm{~mm}$ cubic specimens. Compressive strength was also determined using $50 \mathrm{~mm}$ cubic specimens, in triplicate.

\section{Results and discussion}

\subsection{Pastes produced with aluminium powder as foaming agent}

The mini-slump and density results for the paste mixes with different contents of aluminium powder, and different water/ cement (w/c) ratios, are presented in Figures 3 and 4. It is notable from these figures that no direct correlation between the workability of the fresh paste and the density of the hardened solids is identifiable. It is, however, well known that air entrainment in concretes can often give an improvement in workability (Lamond and Pielert, 2006), as the lower density of the aerated pastes can also lead to a reduction in the slump measurement. It is not likely that rodding for $1 \mathrm{~min}$ with a spatula was sufficient to remove all of the generated gas bubbles from the pastes, and in fact the bubbles remaining in the mix were visible after the mini-slump tests. All pastes tested were able to demonstrate sufficient workability for use in the preparation of mortars.
However, it is also clear from the photographs of cross-sections of the pastes (Figure 5) that the networks of bubbles within these materials are not homogeneously distributed, and that the bubbles are neither spherical nor uniform in size. In optimising the strength of a foamed cement-based material, it is considered important to develop a uniform bubble size distribution (Nambiar and Ramamurthy, 2007).

For this reason, the addition of a surface-active component to stabilise the bubbles was considered desirable; PEG was selected for this purpose, as it is water soluble but a rather weak surfactant (Israelachvili, 1997) (which is desirable to avoid excessive foaming and loss of strength in the hardened materials), retains some stability under the high $\mathrm{pH}$ conditions of a fresh cement paste and showed good performance in preliminary trials of foaming of silicate slurries.

By comparison with Figure 5, it is seen from the photographs in Figure 6 that the PEG was effective in stabilising the

\begin{tabular}{lcrcccc}
\hline Sand & Cement & $\begin{array}{r}\text { Fly } \\
\text { ash }\end{array}$ & $\begin{array}{c}\text { Silica } \\
\text { fume }\end{array}$ & Water & Aluminium & PEG \\
\hline 250 & 100 & 0 & 0 & 40 & 0.90 & 10 \\
250 & 90 & 10 & 0 & 40 & 0.90 & 10 \\
250 & 97 & 0 & 3 & 40 & 0.90 & 10 \\
250 & 87 & 10 & 3 & 40 & 0.90 & 10 \\
250 & 93 & 0 & 7 & 40 & 0.90 & 10 \\
250 & 83 & 10 & 7 & 40 & 0.90 & 10
\end{tabular}

Table 1. Mix designs for mortars (all quantities in grams)

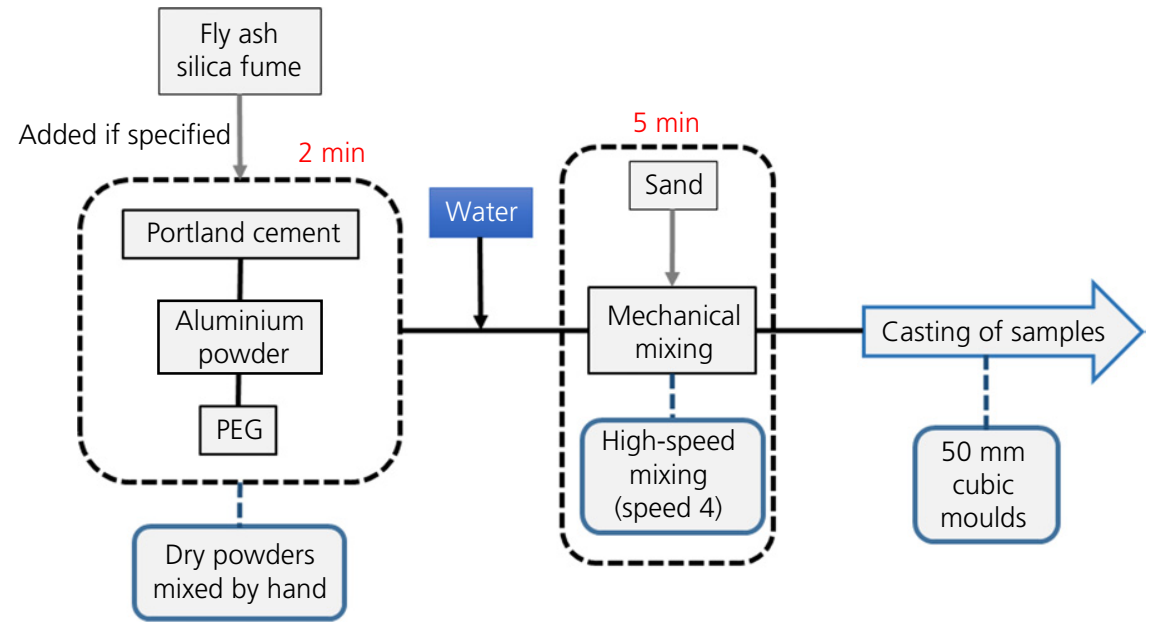

Figure 2. Procedure used for mortar preparation 


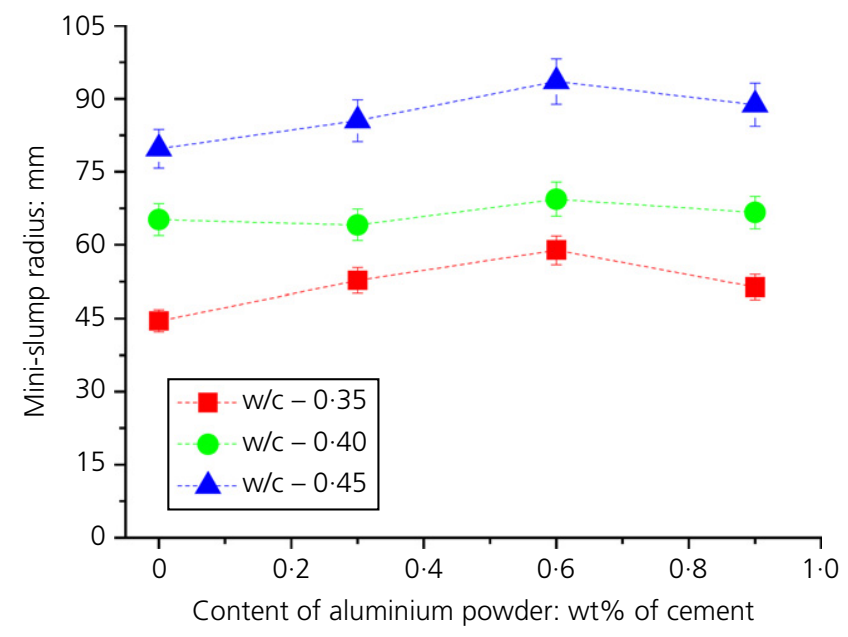

Figure 3. Mini-slump results of Portland cement pastes formulated with different water contents ( $\mathrm{w} / \mathrm{C}$ ratio), as a function of the level of Al powder addition. The mini-slump cone radius was $40 \mathrm{~mm}$

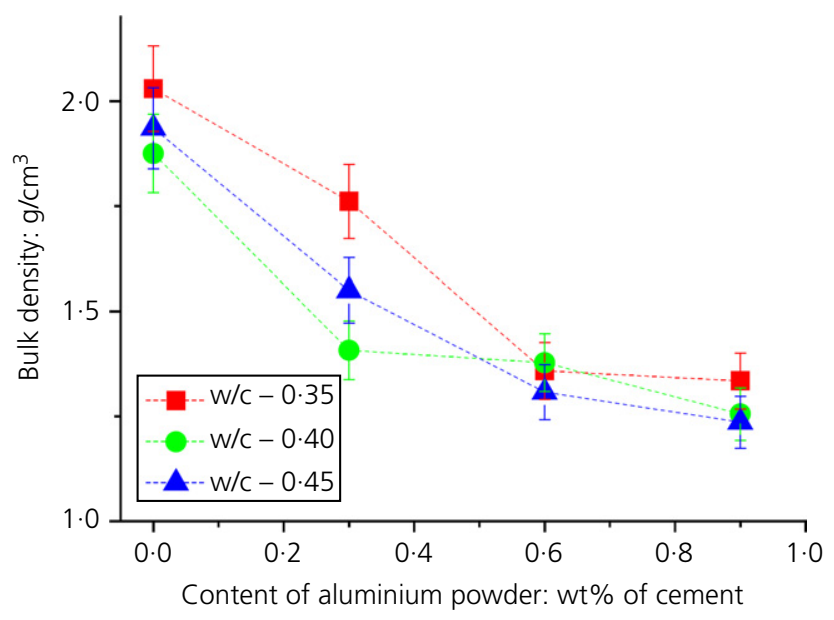

Figure 4. Bulk density of hardened Portland cement pastes formulated with different water contents (w/c ratio), as a function of the level of Al powder addition

bubbles; the bubbles are much more spherical, and significantly smaller than those which are present in the hardened paste in the absence of PEG.

The results presented in Table 2 show that including $10 \mathrm{wt} \%$ PEG does not modify the workability of the paste but is able to significantly reduce the density of the binder, with $\sim 33 \%$ reduction in the bulk density of the hardened paste compared

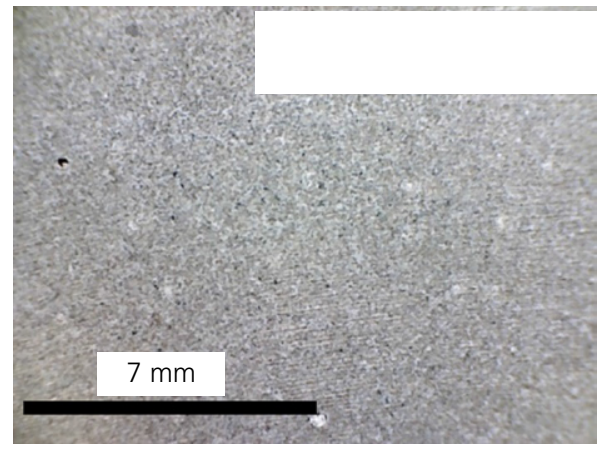

(a)

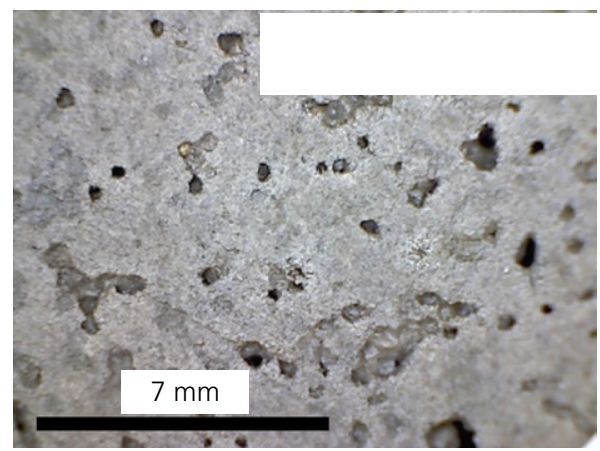

(b)

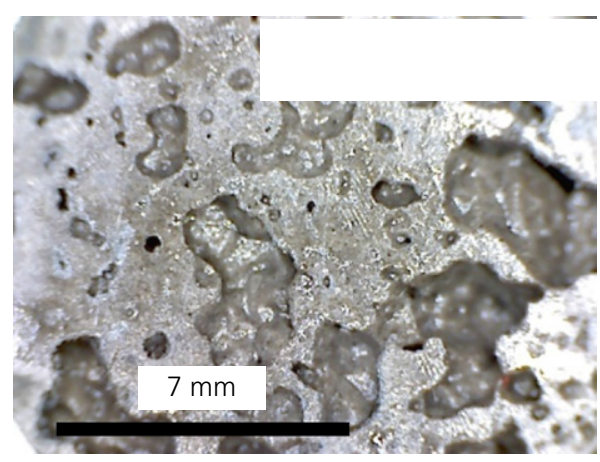

(c)

Figure 5. Photographs of the surfaces of the paste specimens foamed through the addition of Al alone, showing the bubbles within the hardened cement paste matrix. (a) 0 wt \% aluminium; (b) 3 wt \% aluminium; and (c) 9 wt\% aluminium

with the paste with aluminium powder alone; the moulding procedure has clearly removed many of the bubbles generated by aluminium in the absence of a stabiliser, whereas the PEG is effective in retaining the bubbles in the paste as it is poured into the mould and progressively hardens during the early stages of curing. Therefore, tests of mortar mixes were carried out using this combination of foaming agent and bubble stabiliser. 


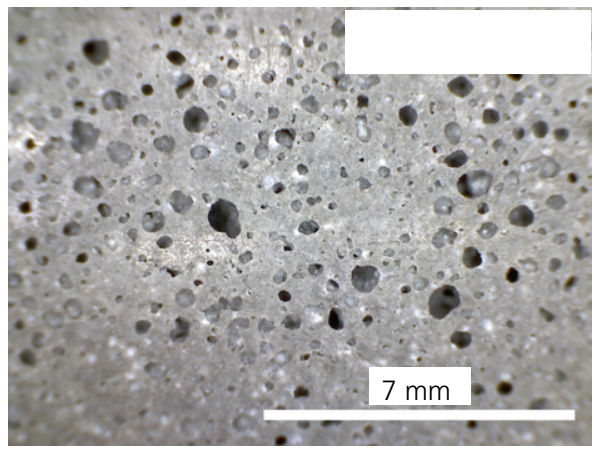

(a)

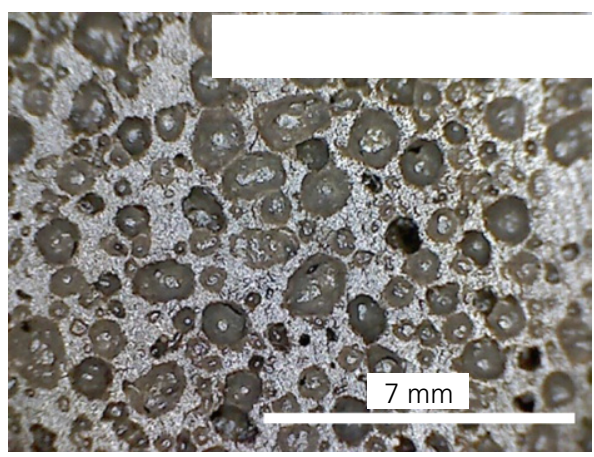

(b)

Figure 6. Surface (a) and cross-sectional (b) photographs of the paste specimens foamed through the addition of Al stabilised by the addition of PEG at w/C 0.40 , showing the bubbles within the hardened cement paste matrix

\begin{tabular}{lccc}
\hline W/c ratio & $\begin{array}{c}\text { Content of PEG: } \\
\text { wt\% of cement }\end{array}$ & $\begin{array}{c}\text { Mini-slump } \\
\text { radius: } \mathrm{mm}\end{array}$ & $\begin{array}{c}\text { Bulk } \\
\text { density: } \mathrm{g} / \mathrm{cm}^{3}\end{array}$ \\
\hline 0.40 & 0 & 66.7 & 1.26 \\
& 10 & 67.8 & 0.85
\end{tabular}

Table 2. Mini-slump and bulk density of foamed pastes with $0.9 \mathrm{wt} \%$ aluminium powder in the presence of PEG as a bubble-stabilising agent

\subsection{Mortars produced with aluminium as foaming agent and PEG as bubble stabiliser}

On the basis of the paste density reduction achievable through the coupled use of aluminium and PEG to generate and stabilise the bubbles, the next parameter tested was the binder mix design. The water/cementitious materials ratio was fixed at $0 \cdot 40$, and fly ash and silica fume were added to the mix in different proportions to determine the influence of each of these components on the bulk density and compressive strength of the hardened mortars. The mortar densities in Figure 7 are significantly higher than the paste densities in Table 2 due to the use of a regular (dense) quartz fine aggregate in the mortar mixes, at a mass ratio of 2.5 to the cementitious component (Table 1). The addition of fly ash consistently reduces the density of the mortar mixes, whereas silica fume densifies the mixes (Figures 7(a) and 7(b)). However, fly ash addition reduces the compressive strength at both 7 and $28 \mathrm{~d}$ (Figures 7(c) and (d)), and so the additional strength generated through silica fume incorporation was beneficial in enabling the materials to approach the range of strength values which would be required for semi-structural applications, up to $25 \mathrm{MPa}$ for the strongest samples tested here. The positive effect of silica fume on compressive strength is more visible in samples without fly ash, consistent with the fact that the mortars have been dosed replacing ordinary Portland cement (OPC) by fly ash; therefore, it is expected to reduce compressive strength at early times of curing as the replacement of OPC by fly ash increases.

To clarify the influence of the mix design on key physical properties of the mortars, Figure 8 shows the relationship between bulk density and compressive strength for the mixes listed in Table 1 as well as some additional mixes developed with higher and lower contents of fly ash during the preliminary mix design process, all at the same water/cementitious materials ratio of $0 \cdot 40$. The relationship between density and compressive strength displays an increasing trend, as expected based on the extensive literature for foamed concretes produced by various mechanical and chemical foaming methods, and as described by a number of mathematical models, where power-law, logarithmic and linear relationships have variously been proposed for different types of foamed concrete (Kearsley and Wainwright, 2002). Considering the error bars shown in Figure 7, the data presented here could be described by any of these types of mathematical relationship with approximately the same degree of precision, and so it is not possible to conclusively state which is the most accurate relationship to describe this set of mortars foamed according to the new methodology presented here. Nonetheless, there is a clear relationship which can be observed by comparison of Figures 7 and 8, where the addition of silica fume yields a lower compressive strength and a higher bulk density; this curve may be used to design materials with the desired combination of density and mechanical performance through adjustment of the blend of cementitious materials with this particular dose of foaming agent and stabiliser.

\section{Conclusions}

This study has presented a methodology by which bubbles can be formed in cementitious pastes through the inclusion of metallic aluminium, and then stabilised by the addition of PEG. This polymer, although considered as a weak surfactant, 


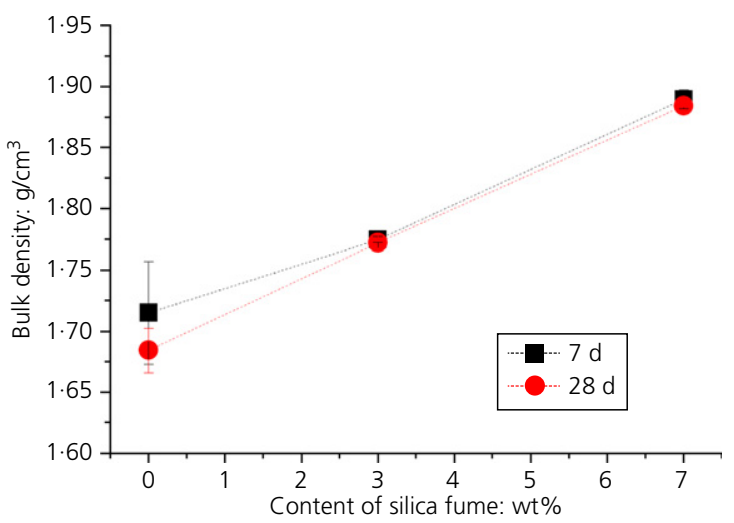

(a)

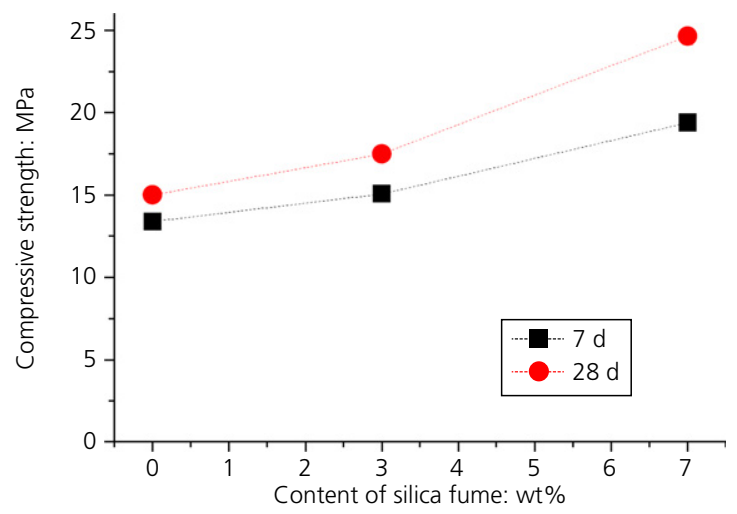

(c)

Figure 7. Bulk density $(a, b)$ and compressive strength (c, d) of hardened Portland cement pastes foamed with $0.9 \mathrm{wt} . \% \mathrm{Al}$ powder and $10 \%$ PEG, blended with fly ash and/or silica fume,

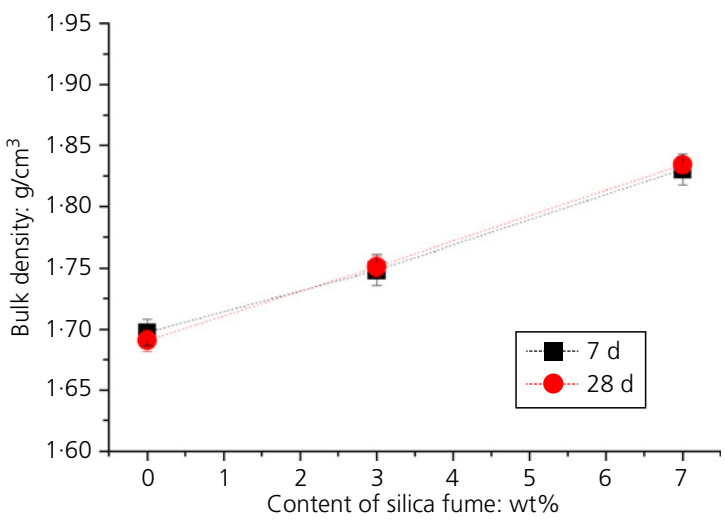

(b)

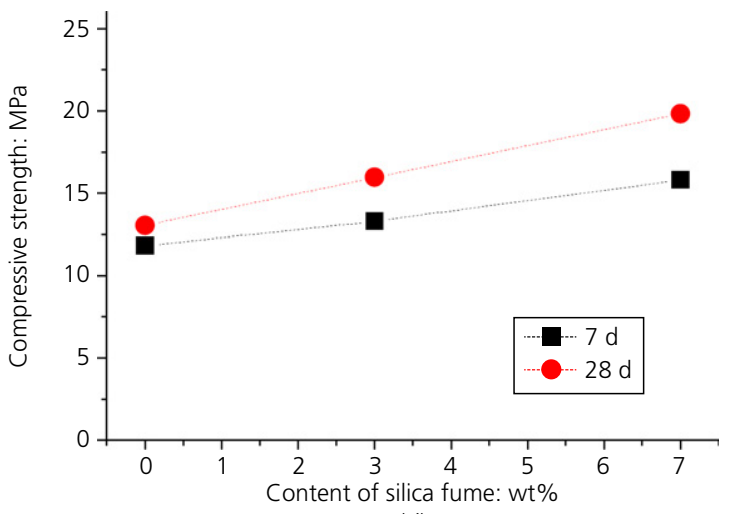

(d)

as a function of the time of curing. $(a, c) 0 \%$ fly ash and (b, d) $10 \%$ fly ash.

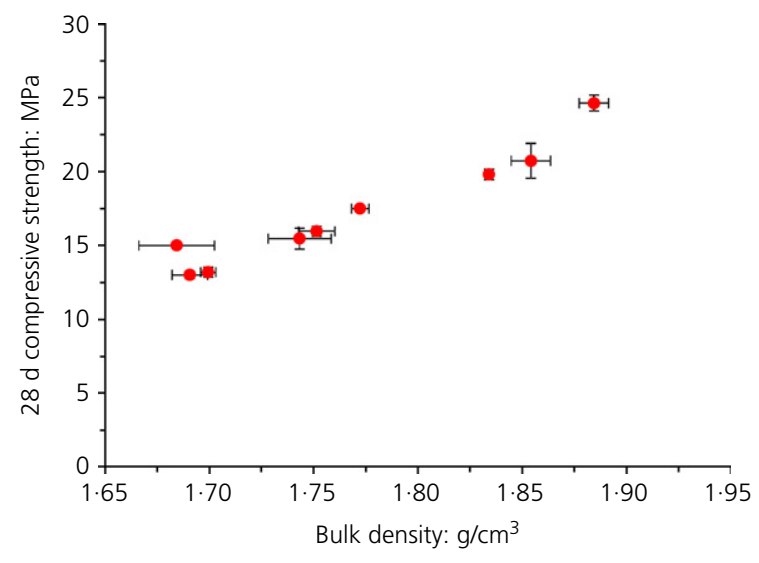

Figure 8. Relationship between bulk density and compressive strength of foamed mortar specimens, containing different fractions of fly ash and silica fume, at a constant content of water, aluminium, and PEG does display sufficient surface activity to prevent the breakdown of the bubbles and the escape of the entrained gases when the material is cast, and begins to harden and develop strength. This methodology, therefore, provides a pathway by which an aluminium-foamed cementitious material can be stabilised at a lower density than would otherwise be possible, while retaining desirable strength characteristics sufficient for semi-structural applications. A mortar compressive strength of $25 \mathrm{MPa}$ at $28 \mathrm{~d}$ can be achieved by this method for a material with a density of $1.90 \mathrm{~g} / \mathrm{cm}^{3}$.

\section{Acknowledgement}

This study was sponsored by the Hyundai Engineering \& Construction Co Ltd (HDEC).

\section{REFERENCES}

ACl (American Concrete Institute) Committee 233 (2000)

Ground granulated blast-furnace slag as a cementitious 
constituent in concrete. American Concrete Institute, Farmington Hills, MI, USA.

Aroni S (ed.) (1993) Autoclaved Aerated Concrete: Properties, Testing, and Design: RILEM Recommended Practicel RILEM Technical Committees 78-MCA and 51-ALC. E\&FN Spon, London, UK.

Aylsworth JW and Dyer FL (1914) Porous Artificial Stone and Its Production. US Patent 1,087,098, Feb.

Bouvet A, Ghorbel E and Bennacer R (2010) The mini-conical slump flow test: analysis and numerical study. Cement and Concrete Research 40(10): 1517-1523.

CEN (European Committee for Standardization) (2005) EN 13263-1:2005+A1:2009: Silica fume for concrete. Definitions, requirements and conformity criteria. CEN, Brussels, Belgium.

CEN (2011) EN 197-1:2011: Cement - part 1: composition, specifications and conformity criteria for common cements. CEN, Brussels, Belgium.

CEN (2012) EN 450-1: Fly ash for concrete - part 1: definitions, specifications and conformity criteria. CEN, Brussels, Belgium.

Israelachvili J (1997) The different faces of poly(ethylene glycol). Proceedings of the National Academy of Sciences of the United States of America 94(16): 8378-8379.

Jones MR and McCarthy A (2005) Preliminary views on the potential of foamed concrete as a structural material.
Magazine of Concrete Research 57(1): 21-31, http://dx.doi. org/10.1680/macr.2005.57.1.21.

Just A and Middendorf B (2009) Microstructure of high-strength foam concrete. Materials Characterization 60(7): 741-748.

Kearsley EP and Wainwright PJ (2002) The effect of porosity on the strength of foamed concrete. Cement and Concrete Research 32(2): 233-239.

Klingner R (2008) Autoclaved aerated concrete. In Developments in the Formulation and Reinforcement of Concrete (Mindess S (ed.)). Woodhead, Cambridge, UK, pp. $1-43$.

Lamond JF and Pielert JH (eds) (2006) Significance of Tests and Properties of Concrete and Concrete-Making Materials. ASTM International, West Conshohocken, PA, USA.

Lee HS, Ismail M, Woo YJ, Min TB and Choi HK (2014) Fundamental study on the development of structural lightweight concrete by using normal coarse aggregate and foaming agent. Materials 7(6): 4536-4554.

Nambiar EKK and Ramamurthy K (2007) Air-void characterisation of foam concrete. Cement and Concrete Research 37(2): 221-230.

Valore RC (1954) Cellular concretes, part 1: composition and methods of preparation. Journal of the American Concrete Institute, Proceedings 50(5): 773-796.

Zhang Z, Provis JL, Reid A and Wang H (2014) Geopolymer foam concrete: an emerging material for sustainable construction. Construction and Building Materials 56: 113-127.

\section{HOW CAN YOU CONTRIBUTE?}

To discuss this paper, please email up to 500 words to the editor at journals@ice.org.uk. Your contribution will be forwarded to the author(s) for a reply and, if considered appropriate by the editorial board, it will be published as discussion in a future issue of the journal.

Proceedings journals rely entirely on contributions from the civil engineering profession (and allied disciplines). Information about how to submit your paper online is available at www.icevirtuallibrary.com/page/authors, where you will also find detailed author guidelines. 